\title{
An assessment of health and social-economic status among Lanoh ethnic sub-group of Orang Asli (indigenous peoples) in Air Bah I village, state of Perak, Malaysia
}

\author{
Yi Xin Cheng ${ }^{1}$, Chee Ping Chong ${ }^{1}$, Chai Fung Kiew ${ }^{1}$, Mohd Baidi Bahari ${ }^{2}$ \\ ${ }^{1}$ Discipline of Clinical Pharmacy, School of Pharmaceutical Sciences, Universiti Sains Malaysia, 11800 Minden, Penang, Malaysia. \\ ${ }^{2}$ Faculty of Pharmacy, AIMST University, 08000 Bedong, Kedah, Malaysia.
}

\begin{tabular}{|c|c|}
\hline ARTICLE INFO & ABSTRACT \\
\hline Article history: & \multirow{11}{*}{$\begin{array}{l}\text { This study was conducted to assess the health and social economic status of Lanoh ethic sub-group of Orang Asli } \\
\text { (indigenous peoples) in Air Bah I village, Malaysia. A one day study which involved health screening and } \\
\text { structured interview was conducted on } 16 \text { April } 2011 \text {. Forty five Orang Asli participated in the health screening. } \\
\text { Fifteen subjects were newly discovered to have high blood pressure while } 5 \text { subjects had high blood glucose } \\
\text { level. Only } 37.8 \% \text { had normal body mass index and } 26.7 \% \text { were pre-obese. Thirteen subjects were interviewed } \\
\text { about their health seeking behavior and knowledge of the proper use of medications. Slightly more than half } \\
\text { ( } 53.8 \% \text { ) of the subjects was uneducated and } 69.2 \% \text { were rubber tappers with the median monthly household } \\
\text { income of RM } 400 \text { (USD } 122.31 \text { ). Approximately } 77 \% \text { of the subjects had visited the health centre for body } \\
\text { checkups. The utilization of herbs as medications ( } 23.1 \% \text { ) was common and the majority ( } 76.9 \% \text { ) said that } \\
\text { traditional medications were safe compared to modern medications. Around } 46 \% \text { of Orang Asli had the opinion } \\
\text { that medications should be kept in the refrigerator and exposed places and } 61.5 \% \text { shared medications with } \\
\text { others. In conclusion, the Lanoh are still categorized under the poverty group and their education level remains } \\
\text { low. Therefore, education intervention is necessary to improve their knowledge on the proper use of medications. }\end{array}$} \\
\hline Received on: 05/06/2014 & \\
\hline Revised on: 26/08/2014 & \\
\hline Accepted on: 19/09/2014 & \\
\hline Available online: $30 / 10 / 2014$ & \\
\hline Key words: & \\
\hline Orang Asli, indigenous & \\
\hline peoples Malaysia, health & \\
\hline status, health seeking & \\
\hline & \\
\hline & \\
\hline
\end{tabular}

\section{INTRODUCTION}

Orang Asli are the indigenous minority peoples of Peninsular Malaysia (Asian Indigenous and Tribal Peoples Network, 2008) with a population of 141,230 people or $0.5 \%$ of the national population in 2008 (Ministry of Rural and Regional Development, 2008a). The Orang Asli are mainly classified into 3 major groups namely the Senoi, Proto-Malay and Negrito based on their spoken languages (Asian Indigenous and Tribal Peoples Network, 2008; Nicholas, 2010). The Negritos, the smallest group which comprises of only $3 \%$ of the Orang Asli population, are mostly found in the northern region of the peninsular Malaysia. The Lanoh ethnic, who speak a central Aslian language, is grouped under the Negritos (Khor and Shariff, 2008).

* Corresponding Author

Chee Ping Chong, Discipline of Clinical Pharmacy, School of

Pharmaceutical Sciences, Universiti Sains Malaysia, 11800 Minden,

Penang, Malaysia.Email: jjueping@gmail.com
The Lanoh ethnic resides at the remote areas of the northern region of the state of Perak and their population was only 359 people in year 2005 (Department of Orang Asli Development, 2014). Orang Asli are among the marginalized group who are still left behind the mainstream development and do not have the opportunity underserved to enjoy the fruits of national developments over the decades. In terms of socioeconomic aspects, $17.75 \%$ are still under poverty and approximately one third of them were in the hardcore poverty group in 2008, which is much higher if compared to the national poverty rate of $3.8 \%$ (Department of Statistics Malaysia, 2012; Ministry of Rural and Regional Development, 2008b). In fact, their education level is generally low whereby most Orang Asli only attained primary education (Michael and Chuen, 2012; Kamaruddin, 2008) and their dropout rate was high $(39.1 \%)$ as reported after their primary education (Ministry of Rural and Regional Development, 2008c). In general, Orang Asli often have limited access to healthcare services. This is mostly due to the geographical constraint and poverty. 
While the infectious disease, such as tuberculosis and malaria, occurred more prevalent among them, non communicable diseases, such as diabetes mellitus and hypertension also plagued them although such cases were discovered to be low compared to those in the urban area (Nicholas, 2010). Health screening plays a vital role in the early detection, identification and controlling of chronic diseases and its associated risk factors among Orang Asli (Strong et al., 2005). This is of utmost important in view of the changing lifestyle and disease patterns together along with their resettlement and the government's efforts to integrate them into the mainstream development (Nicholas, 2010). Furthermore, newly discovered cases from health screening can be referred for further management to reduce disease complications and health burden on the country. Currently, little is known about the Lanoh ethic with regard to their health condition, health seeking behavior and socioeconomic status. This present study was carried out to assess the health and social-economic status of the Lanoh subgroup of Orang Asli population in Air Bah I village, in Lenggong district, state of Perak, Malaysia. The result of this study would help in the development of strategies and policies to assist in the development of this minority sub-group of indigenous peoples.

\section{METHODS}

A one day study, divided into two different parts, was conducted in Air Bah I village, Lenggong, state of Perak, on 16 April 2011 with the approval of the Department of Orang Asli Development Malaysia. Air Bah I is a small village which consists of 40 families with a total population of 205 Orang Asli with 81 of them who are 18 years old and below. The distribution of the male and female is almost equal, with 53.2\% ( $\mathrm{n}=109)$ are males (Department of Statistic Malaysia, 2011). One week before the study, Tok Batin (the chief of the village) and all the Orang Asli were informed of the health screening and they were asked to fast for 10 hours prior to the health screening on the next day. The banners to advertise the health screening were hanged at the main sites of the village. Subjects of 18 years and above were recruited through convenient sampling method. Informed consent was obtained from the subjects prior to the health screening and an interview was carried out. The first part of the study involved health screening tests including blood pressure, body mass index (BMI), body fat percentage $(\% \mathrm{BF})$, visceral fat accumulation (VFA), peak expiration flow rate (PEFR) and blood glucose level measurements. Random blood sugar level measurement was conducted during the health screening for the subjects who did not fast overnight as instructed. For those who fasted overnight, only fasting blood sugar measurement was performed. The health screening was conducted by 7 registered pharmacists from the School of Pharmaceutical Sciences, Universiti Sains Malaysia. The blood pressure was measured with a British Hypertension Society-validated electronic BP sets (Omron ${ }^{\circledR}$ Model HEM-2703). The subjects were seated, well rested for 5 minutes and one arm was placed on a table at the same level to the heart for measurement. The BMI, \%BF and VFA measurements were performed by using bioelectrical impedance analysis (Omron ${ }^{\circledR}$ Model HBF-362). The PEFR was measured using Mini-Wright ${ }^{\circledR}$ peak flow meter while the blood glucose was measured with AccuCheck $^{\circledR}$ Advantage meter. In the second part of the study, a structured interview was conducted using validated structured questions. Face and content validation of the questions were done by 3 experts from the School of Pharmaceutical Sciences, Universiti Sains Malaysia. The questions were developed based on a literature review. The indigenous peoples were assessed on their social-economic status, health seeking behavior and knowledge about the proper use of medications. All the subjects were verbally asked exactly the same questions in Malay language with a fixed range of answers. Further explanation was given to the subjects if they did not understand the questions. The questionnaires were filled in by the interviewers on behalf of the subjects after interviewing them. All the data collected were entered into SPSS ${ }^{\circledR}$ Version 16 for analysis purpose and the descriptive statistic was used.

Table 1: Demographic of the health screening subjects

\begin{tabular}{lc}
\hline Characteristics & $\mathbf{N}(\boldsymbol{\%})$ \\
\hline Gender & $12(26.7)$ \\
\hline Male & $33(73.3)$ \\
\hline Female & \\
\hline Age group, years & $18(40.0)$ \\
\hline $18-29$ & $14(31.1)$ \\
$30-39$ & $8(17.8)$ \\
$40-49$ & $3(6.7)$ \\
$50-59$ & $1(2.2)$ \\
$60-69$ & $1(2.2)$ \\
Missing data & \\
\hline Marital status & $8(17.8)$ \\
\hline Single & $34(75.6)$ \\
Married & $3(6.7)$ \\
Missing data & \\
\hline Employment position & $16(35.6)$ \\
\hline Housewife & $8(17.8)$ \\
Not working & $18(40.0)$ \\
Working & $3(6.7)$ \\
Missing data & \\
\hline Past medical history & $4(8.9)$ \\
\hline Hypertension & $3(6.7)$ \\
Diabetes and hypertension & $1(2.2)$ \\
Diabetes & $1(2.2)$ \\
Malaria & $1(2.2)$ \\
Dengue & $1(2.2)$ \\
Cancer & $1(2.2)$ \\
Tuberculosis & $33(73.3)$ \\
No history & \\
\hline Family history & $3(6.7)$ \\
\hline Tuberculosis & $2(4.4)$ \\
Hypertension & $1(2.2)$ \\
Asthma & $1(2.2)$ \\
Cardiovascular disease and tuberculosis & $1(2.2)$ \\
Diabetes, hypertension and cardiovascular disease & $1(2.2)$ \\
Epilepsy & $36(80.0)$ \\
No history & \\
\hline & \\
\hline & \\
\hline
\end{tabular}

\section{RESULTS}

\section{Demographic of the health screening subjects}

A total of 45 Orang Asli adults participated in the health screening. The response rate was $36 \%$ of the total of 124 adults Orang Asli in the village. Most of the subjects were females 
(73.3\%) and aged less than 39 years old $(71.1 \%)$. Seventy five percent of the subjects were married and $35.6 \%$ were housewives. The majority of the subjects $(73.3 \%)$ claimed to have no comorbidities.

However, $8.9 \%$ of the subjects had hypertension while $6.7 \%$ had hypertension together with diabetes mellitus. Most of the subjects $(80.0 \%)$ claimed that they had no family history of illness and only $6.7 \%$ had a family history of tuberculosis (Table 1).

Table 2: Results of the screening tests.

\begin{tabular}{|c|c|}
\hline Characteristics & $\mathbf{N}(\%)$ \\
\hline \multicolumn{2}{|l|}{ Blood pressure $(\mathrm{mmHg})$} \\
\hline$<120$ and $<80$ (Optimal) & $17(37.8)$ \\
\hline 120-139 and/or 80-89 (Prehypertension) & $13(28.9)$ \\
\hline 140-159 and/or 90-99 (Hypertension Stage 1) & $9(20.0)$ \\
\hline 160-179 and/or 100-109 (Hypertension Stage 2) & $5(11.1)$ \\
\hline$\geq 180$ and $/$ or $\geq 110($ Hypertension Stage 3$)$ & $1(2.2)$ \\
\hline \multicolumn{2}{|l|}{ Body mass index $\left(\mathrm{kg} / \mathrm{m}^{2}\right)$} \\
\hline$<18.5$ (Underweight) & $3(6.7)$ \\
\hline 18.5 to 22.9 (Normal range) & $17(37.8)$ \\
\hline 23.0 to 27.4 (Pre-obese) & $12(26.7)$ \\
\hline 27.5 to 34.9 (Obese I) & $7(15.6)$ \\
\hline Missing data & $6(13.3)$ \\
\hline \multicolumn{2}{|l|}{ Body fat percentage $(\%)$ - Male } \\
\hline$<10.0$ (Low) & $1(8.3)$ \\
\hline 10 to $<20.0$ (Normal) & $6(50.0)$ \\
\hline 20 to $<25.0$ (High) & $3(25.0)$ \\
\hline$\geq 25.0$ (Slightly high) & $1(8.3)$ \\
\hline Missing data & $1(8.3)$ \\
\hline \multicolumn{2}{|l|}{ Body fat percentage (\%) - Female } \\
\hline$<20.0$ (Low) & $1(3.0)$ \\
\hline 20 to $<30.0$ (Normal) & $16(48.5)$ \\
\hline 30 to $<35.0$ (High) & $7(21.2)$ \\
\hline$\geq 35.0$ (Slightly high) & $9(27.3)$ \\
\hline \multicolumn{2}{|l|}{ Visceral fat accumulation } \\
\hline 1 to 9 (Normal) & $37(82.2)$ \\
\hline 10 to 14 (Slightly high) & $6(13.3)$ \\
\hline$>15$ (High) & $1(2.2)$ \\
\hline Missing data & $1(2.2)$ \\
\hline \multicolumn{2}{|l|}{ Fasting blood glucose, $\mathrm{mmol} / \mathrm{L}(\mathrm{N}=25)$} \\
\hline$<6.1$ & $24(96)$ \\
\hline 6.1 to 6.9 & $0(0)$ \\
\hline$\geq 7.0$ & $1(4)$ \\
\hline \multicolumn{2}{|l|}{ Random blood sugar, $\mathrm{mmol} / \mathrm{L}(\mathrm{N}=19)$} \\
\hline$<7.8$ & $15(78.9)$ \\
\hline 7.8 to 11.0 & $1(5.3)$ \\
\hline$\geq 11.1$ & $3(15.8)$ \\
\hline \multicolumn{2}{|l|}{ Peak expiration flow rate } \\
\hline Low & $3(6.7)$ \\
\hline Normal & $36(80.0)$ \\
\hline Missing data & $6(13.3)$ \\
\hline
\end{tabular}

\section{Results of health screening tests}

From the health screening, it was found that $37.8 \%$ of the subjects had optimal blood pressure and $28.9 \%$ of the subjects were in prehypertension stage. However, $23.3 \%(n=15)$ of the subjects had blood pressure of 140-159 and/or $90-99 \mathrm{mmHg}$ or higher. Only 6 among these 15 subjects had hypertension. Those with abnormal blood pressure were referred to physicians for further investigation. Only $37.8 \%$ of the subjects had normal BMI and quite a large proportion of the subjects were pre-obese $(26.7 \%)$. Half of the male subjects $(50.0 \%)$ and almost half of the female subjects $(48.5 \%)$ had normal \%BF. Eighty two percent of the subjects had normal VFA. The blood glucose level of those who had fasted was less than $6 \mathrm{mmol} / \mathrm{L}$ except for $14.4 \mathrm{mmol} / \mathrm{L}$ for a subject who had no history of diabetes mellitus. Regarding random blood glucose, $78.9 \%$ of the subjects had a normal level below $7.8 \mathrm{mmol} / \mathrm{L}$.

However, $21.1 \%(n=4)$ of the subjects had random blood glucose level of more than $7.8 \mathrm{mmol} / \mathrm{L}$, whom 2 among them had no history of diabetes mellitus. One subject with random blood glucose of $20.6 \mathrm{mmol} / \mathrm{L}$ was a diabetic patient and another subject with random blood glucose of $13.1 \mathrm{mmol} / \mathrm{L}$ was also a known case of diabetes mellitus and hypertension. All the subjects with abnormal glucose level were referred to physicians for further management. When screened for PEFR, $80.0 \%$ of the subjects were found to have normal value (Table 2).

\section{Demographic and social-economic status of the subjects interviewed}

In the second part of study, a total of 13 subjects were willing to participate in the interview. The response rate was $10.5 \%$ of the total of 124 Orang Asli adults in the village. Approximately $61 \%$ of the subjects were males and $54 \%$ were 39 years old and below. Most subjects were married (92.3\%) with the median number of children of 4.5. In terms of education, more than half $(53.8 \%)$ of the subjects were uneducated and $46.2 \%$ went through primary education only. Sixty nine percent of the subjects interviewed were employed as rubber tappers with median monthly household income of RM 400 (USD 122.31). A majority $(61.5 \%)$ of the subjects had 3 meals per day and none of them consumed alcohol (Table 3 ).

Table 3: Demographic and social-economic status of the subjects interviewed.

\begin{tabular}{|c|c|}
\hline Characteristics & $\mathbf{N}(\%)$ \\
\hline \multicolumn{2}{|l|}{ Gender } \\
\hline Male & $8(61.5)$ \\
\hline Female & $5(38.5)$ \\
\hline \multicolumn{2}{|l|}{ Age group, years } \\
\hline $18-29$ & $4(30.8)$ \\
\hline $30-39$ & $3(23.1)$ \\
\hline $40-49$ & $2(15.4)$ \\
\hline $50-59$ & $3(23.1)$ \\
\hline $60-69$ & $1(7.7)$ \\
\hline \multicolumn{2}{|l|}{ Marital status } \\
\hline Single & $1(7.7)$ \\
\hline Married & $12(92.3)$ \\
\hline \multicolumn{2}{|l|}{ Education level } \\
\hline Primary school & $6(46.2)$ \\
\hline Not educated & $7(53.8)$ \\
\hline \multicolumn{2}{|l|}{ Employment status } \\
\hline Housewife & $4(30.8)$ \\
\hline Rubber tapper & $9(69.2)$ \\
\hline \multicolumn{2}{|c|}{ Number of meals per day } \\
\hline 2 & $4(30.8)$ \\
\hline 3 & $8(61.5)$ \\
\hline 4 or more & $1(7.7)$ \\
\hline \multicolumn{2}{|c|}{ Alcohol consumption } \\
\hline Yes & $0(0.0)$ \\
\hline No & $13(100)$ \\
\hline
\end{tabular}


Table 4: Health seeking behavior and knowledge about the proper use of medications.

\begin{tabular}{|c|c|}
\hline Question & $\mathbf{N}(\%)$ \\
\hline \multicolumn{2}{|l|}{ 1. I used to do body check up at health centre. } \\
\hline Yes & $10(76.9)$ \\
\hline No & $3(23.1)$ \\
\hline \multicolumn{2}{|l|}{ 2. Where do you obtain treatments when sick? } \\
\hline Government hospital or clinic & $6(46.2)$ \\
\hline Herbal treatment & $2(15.4)$ \\
\hline Community pharmacy & $2(15.4)$ \\
\hline Government hospital or clinic and herbal treatment & $2(15.4)$ \\
\hline Government hospital or clinic and community pharmacy & $1(7.7)$ \\
\hline \multicolumn{2}{|c|}{ 3. Where do you obtain medicine from places other than hospitals and clinics? } \\
\hline Community pharmacy & $5(38.5)$ \\
\hline Herbs from jungle & $3(23.1)$ \\
\hline Community pharmacy and traditional medicine shop & $1(7.7)$ \\
\hline No other option & $1(7.7)$ \\
\hline Visiting nurse from Ministry of Health & $1(7.7)$ \\
\hline Missing data & $2(15.4)$ \\
\hline \multicolumn{2}{|c|}{$\begin{array}{l}\text { 4. Do you think traditional medications have adverse effects compared to modern medications? (Traditional medications mean herbs from the } \\
\text { natural surroundings of the village) }\end{array}$} \\
\hline Yes & $2(15.4)$ \\
\hline No & $10(76.9)$ \\
\hline Not sure & $1(7.7)$ \\
\hline \multicolumn{2}{|c|}{ 5. Do you have problem in identifying which medication to be taken when there is more than one medication prescribed? } \\
\hline Yes & $6(46.2)$ \\
\hline No & $7(53.8)$ \\
\hline \multicolumn{2}{|c|}{ 6. Where do you place or store your medications? (can choose more than 1 answer) } \\
\hline Refrigerator & $3(23.1)$ \\
\hline Sheltered places & $3(23.1)$ \\
\hline Exposed place & $3(23.1)$ \\
\hline In a box & $2(15.4)$ \\
\hline In the cupboard & $2(15.4)$ \\
\hline \multicolumn{2}{|l|}{ 7. Do you share your medications with other family members? } \\
\hline Yes & $8(61.5)$ \\
\hline No & $5(38.5)$ \\
\hline \multicolumn{2}{|l|}{ 8. Are you willing to pay for health expenditure? } \\
\hline Yes & $4(30.8)$ \\
\hline No & $8(61.5)$ \\
\hline Missing data & $1(7.7)$ \\
\hline
\end{tabular}

\section{Health seeking behavior and knowledge about proper use of medications}

When interviewed of health seeking behavior, $76.9 \%$ of the subjects were discovered to have visited the health centre for body checkups. The majority $(69.2 \%)$ obtained treatments from doctors in government hospitals or clinics when they were sick. When asked about the source where they obtained medications apart from government hospitals and clinics, 38.5\% answered that they obtained from community pharmacy while $23.1 \%$ obtained herbs from the jungle. The majority of the subjects interviewed $(76.9 \%)$ were in the opinion that traditional medications do not have adverse effects compared to medications from doctors or pharmacists. When questioned about their knowledge on the storage of oral medications, $23.1 \%$ answered that oral medications should be kept in the refrigerator. Others said that medications should be placed in sheltered places $(23.1 \%)$, in a box $(15.4 \%)$ and in the cupboard (15.4\%). Around $46 \%$ of them had difficulty in identifying their medications when they were prescribed more than one. The majority $(61.5 \%)$ shared their medications with other family members. When assessing their willingness to pay for healthcare expenditure, $61.5 \%$ were not willing to do so. The average healthcare expenses were RM 25 (USD 7.64) per month (Table 4).

\section{DISCUSSION}

\section{Health status of subjects from health screening}

This present study found that the prevalence of hypertension and diabetes mellitus among the Lanoh were $15.6 \%$ and $8.9 \%$ respectively. The prevalence of diabetes mellitus in this study was lower compared to the total of $16.8 \%$ found in a recent study conducted among indigenous peoples in 4 rural resettlement areas 60-90 km away from Kuala Lumpur city, Malaysia (Mohamud and Suraiami, 2010). From the present health screening, a total of 9 and 3 subjects respectively were newly discovered to have high blood pressure and high glucose level. This can be attributed to low sense of awareness and lack of regular body check up for early detection of these diseases. The Orang Asli was previously noted to have higher occurrence of tuberculosis. The reported incidence of tuberculosis among Orang Asli in the state of Perak was about 240 per 100,000 or 5.5 times that of the Perak overall population (Devaraj, 1999). In the present study, only 1 subject claimed to have a history of tuberculosis while another 3 subjects had their family history of this infectious disease. Considering other infectious disease, only one malaria case was noted in the past medical history of the subjects which was much lower than the point prevalence of malaria $(24.2 \%)$ as revealed in the Orang Asli community in the state of Pahang, 
Malaysia (Kaur, 2009). These infectious diseases can be easily controlled with modern medication treatment. Healthcare services should be made available to them and this is of utmost importance as they are more geographically segregated or isolated.

The present screening showed that only $15.6 \%$ of the subjects were obese and the $\% \mathrm{BF}$ was found to be normal in approximately half of the male and female. The prevalence of obesity in the present study was discovered to be much lower than the reported nationwide data in which $30 \%$ of the population in Malaysia was obese (Lim, 2008). This can be attributed to their simple lifestyles and diet which was obtained mostly from the natural resources. The normal BMI, \%BF and VFA value of the majority of this Orang Asli population reduce their risks of getting diabetes mellitus and cardiovascular diseases which are prevalent in urban populations (Ikram et al., 2004; Shea et al., 2012; Kanai et al., 1990).

\section{Social-economic status of the subjects interviewed}

This study discovered that education level of the Orang Asli was low. While approximately half of Orang Asli in Kamping Air Bah I were uneducated, the other half had primary school education only. Some scholars reported that poverty, contrast in pedagogy and culture and the imperfections of education systems were the main reasons of high dropout rate (Michael and Chuen, 2012).

The statistics in 2008 had shown that $39.1 \%$ of Orang asli students who finished six years of primary education did not enter first year of secondary education (Ministry of Rural and Regional Development, 2008c). Besides, as high as $47.8 \%$ of students who entered first year of secondary education did not finish until their fifth year of secondary education (Ministry of Rural and Regional Development, 2008c). The education issues among Orang Asli should be overcome by creating awareness of the importance of education for their future betterment while providing them financial support for education in view of their high poverty rate (Nicholas, 2010).

Poverty is one of the main problems which affect the health and social life of Orang Asli. Although the national poverty rate of Malaysia has declined over the years, approximately one third of Orang Asli are still in the hardcore poverty group in 2008 (Ministry of Rural and Regional Development, 2008c). In the present study, it was discovered that most of the Orang Asli worked as rubber tappers with low income. This finding is comparable to a study conducted by Anita et al. which revealed that the majority of Orang Asli in Penisular Malaysia (72.7\%) had a household income of RM 500 (USD 152.88) and below per month (Anita et al., 2007).

With the median number of children of 4.5 per household, this meager income would make it difficult for Orang Asli in this study to pay for their children's education and healthcare expenses. Also, the economic constraint is the main factor that allows only $31 \%$ of them to be willing to pay for healthcare expenditure. Measures of eradicating poverty had been carried out by the Malaysian government through organized resettlement program, economic and social development program by the Department of Orang Asli Development Malaysia (Department of Orang Asli Development, 2012). However, the effectiveness of these programs in improving the poverty status of Orang Asli should be continually evaluated.

\section{Health seeking behavior and knowledge about the proper use of medications}

The subjects in this study had good health seeking behavior as the majority of them had undergone body checkups and obtained treatment from hospitals and clinics when they were sick. This showed that they were willing to get modern treatment instead of remaining in the denial of the illness. This finding is comparable to the result of a study where a high percentage (88.5\%) of Orang Asli community at Kuala Boh, state of Selangor went for regular health checkups (Othman et al., 2012). The subjects from this study still believe in traditional medications such as herbal from the jungle.

This study also showed that most of them were in the opinion that traditional medications would not pose harm to their health. Studies of Orang Asli from other parts of peninsular Malaysia also reported the use of traditional medications for healing their illness as a practice passed from generations to generations (Ong et al., 2012; Mohammad et al., 2012). Nevertheless, a further study on the use of these traditional medications should be done especially in the area of interaction with modern medications since the indigenous peoples would go for modern treatment.

This study discovered that Orang Asli had poor knowledge of the proper storage and use of medications. Up to $23 \%$ of the subjects had the wrong perception that oral medications should be kept in a refrigerator. Also, the majority $(61.5 \%)$ of them had the wrong practice of sharing their medications with other family members. Lack of awareness on medication safety may be attributed to poor education level and unawareness of the consequences of these improper practices. Therefore, good counseling and education on the proper use of medications is essential for the Orang Asli to avoid the harmful effects of especially the sharing of medications. While education, poverty and land rights (Asian Indigenous and Tribal Peoples Network, 2008; Nicholas, 2010) are among the issues most explored among Orang Asli, more assessment of their knowledge on medications need to be done, such as the usage of modern medications which is common among them nowadays.

\section{Limitation}

The main challenge faced by the study was the lack of responses from the indigenous peoples. The Lanoh are shy in nature and due to the language and culture barriers, most of them were reluctant to participate in the health screening and interview. However, they were capable of understanding simple Malay language as used in our interview. Hence, the study is valuable in providing a suggestive baseline data on the health and socialeconomic status of this minority sub-group of indigenous peoples. 


\section{CONCLUSION}

The health screening has detected new cases of high blood glucose and high blood pressure among the Lanoh. In terms of social-economic status, the Lanoh are still under the poverty group and their education level remains low. A majority of them seek modern treatment although the use of traditional medications is part of their health seeking behavior. Education intervention is necessary to improve their knowledge on the proper use of medications.

\section{ACKNOWLEDGEMENT}

This study is supported by a grant from the Division of Industry and Community Network, Universiti Sains Malaysia.

\section{Conflict of interest}

The authors declare that they have no conflict of interest.

\section{REFERENCES}

Anita S, Zahir WM, Sa'iah A, et al. HIV/AIDS knowledge, attitudes and risk behaviours among Orang Asli in Peninsular Malaysia. Med J Malaysia. 2007;62: 227-233.

Asian Indigenous and Tribal Peoples Network. 2008. The Department of Orang Asli Affairs, Malaysia: an agency for assimilation (1st ed). Asian Indigenous and Tribal Peoples Network, New Dehli.

Department of Orang Asli Development. 2012. Initiative: arranged placement programme, economic and social development programme. Department of Orang Asli Development, Putrajaya. [ONLINE] Available at: http://www.jakoa.gov.my. [Accessed 11 Sept 2012].

Department of Orang Asli Development. 2014. Orang Asli Negrito. Department of Orang Asli Development, Putrajaya. [ONLINE] Available at: http://damak.jakoa.gov.my/index.php?mid=1\&vid=3. [Accessed 19 May 2014].

Department of Statistic Malaysia. 2011. Banci 4 kampung pinggir bandar Gerik tahun 2011. Department of Statistics Malaysia, Putrajaya.

Department of Statistics Malaysia. 2012. Income and expenditure poverty profile. Department of Statistics Malaysia, Putrajaya. [ONLINE] Available at: http://www.statistics.gov.my. [Accessed $8 \mathrm{Sept}$ 2012].

Devaraj J. 1999. Between myth and reality: why are Orang Asli more prone to illness? World Conference of Primary Care Physicians, Kuching, Malaysia.

Ikram IS, Noor MI, Kamaruddin NA, et al. 2004. Malaysian clinical practice guidelines on management of obesity 2004. Ministry of Health Malaysia, Kuala Lumpur.

Kamaruddin K. Educational policy and opportunities of Orang Asli: a study on indigenious people in Malaysia. J Hum Resource Adult Learn. 2008;4:86-97.

Kanai H, Matsuzawa Y, Kotani K, et al. Close correlation of intra-abdominal fat accumulation to hypertension in obese women. Hypertension. 1990;16:484-490.
Khor GL, Shariff ZM. The ecology of health and nutrition of Orang Asli (Indigenous people) women and children in Peninsular Malaysia. Tribes Tribals. 2008;2:66-77.

Kaur G. Malaria endemicity in an Orang Asli community in Pahang, Malaysia. Trop Biomed. 2009;26:57-66.

Lim WW. 2008. Less pain without obesity. The Star Online. [ONLINE] Available

at http://thestar.com.my/health/story.asp?file=/2008/6/29/health/21600616\&s ec=health. [Accessed 3 August 2012].

Michael E, Chuen EM. Education and health awareness among indigenious people: a study in Perak, Malaysia. ARPN J Sci Tech. 2012;2:745-749.

Ministry of Rural and Regional Development. 2008a. Jumlah penduduk Orang Asli mengikut negeri. Ministry of Rural and Regional Development, Putrajaya. [ONLINE] Available at: http://www.rurallink.gov.my/c/document_library/get_file?uuid=a333fd84d9dc-4565-aa7e-4c1a2875f977\&groupId=80191. [Accessed 3 Sept 2012].

Ministry of Rural and Regional Development. 2008b. Status kemiskinan penduduk Orang Asli, 2000-2008. Ministry of Rural and Regional Development, Putrajaya. [ONLINE] Available at: http://www.rurallink.gov.my. [Accessed 3 Sept 2012].

Ministry of Rural and Regional Development. 2008c. Bilangan dan peratus keciciran pelajar Orang Asli, 1994-2008. Ministry of Rural and Regional Development, Putrajaya. [ONLINE] Available at: http://www.rurallink.gov.my. [Accessed 3 Sept 2012].

Mohammad NS, Milow P, Ong HC. Traditional medicinal plants used by the Kensiu tribe of Lubuk Ulu Legong, Kedah, Malaysia. Stud Ethno-Med. 2012;6:149-153.

Mohamud WNW, Suraiami M. Prevalence of diabetes, impaired fasting glucose and metabolic syndrome among female Orang Asli community in Peninsular Malaysia. Int J Diab Dev Ctries. 2010;30:118122.

Nicholas C. 2010. Orang Asli: rights, problems, solutions. Human Rights Comission of Malaysia (Suhakam), Kuala Lumpur.

Ong HC, Lina E, Milow P. Traditional knowledge and usage of medicinal plants among the Semai Orang Asli at Kampung Batu 16, Tapah, Perak, Malaysia. Stud Ethno-Med. 2012;6:207-211.

Othman CN, Azinur R, Lamin C et al. Lifestyle related diseases amongst Orang Asli in Peninsular Malaysia-case study. Soc Behav Sci. 2012;36:383-392.

Shea JL, King MTC, Yi Y, et al. Body fat percentage is associated with cardiometabolic dysregulation in BMI-defined normal weight subjects. Nutr Metab Cardiovasc Dis. 2012;22:741-747.

Strong K, Wald N, Miller A, et al. Current concepts in screening for noncommunicable disease: World Health Organization Consultation Group Report on methodology of noncommunicable disease screening. J Med Screen. 2005;12:12-19.

\section{How to cite this article:}

Yi Xin Cheng, Chee Ping Chong, Chai Fung Kiew, Mohd Baidi Bahari. An assessment of health and social-economic status among Lanoh ethnic sub-group of Orang Asli (indigenous peoples) in Air Bah I village, state of Perak, Malaysia. J App Pharm Sci, 2014; 4 (10): 032-037. 